\title{
Association between the Quality of Non-Face-to-Face Classes, Learning Outcomes and Learning Emotion for Health Students due to COVID-19
}

\author{
Hae-Soo Yoon ${ }^{1}$, Hyun-Jung Lee ${ }^{2}$, Su-Jin Moon ${ }^{2}$, Kyung-Hee Lee ${ }^{2}$, Je-Hyeok Lim² ${ }^{2}$ Jong-Hwa Jang ${ }^{1,2}$ \\ ${ }^{1}$ Department of Public Health, Graduate School, Dankook University, Korea \\ ${ }^{2}$ Department of Dental Hygiene, College of Public Health Sciences, Dankook University, Korea
}

\begin{abstract}
Objective: Currently, non-face-to-face classes are dramatically on the increase due to COVID-19. This study was conducted to investigate the preferred lecture types in non-face-to-face classes and factors affecting class satisfaction among health students and to understand their correlation.

Method: In this study, a self-report survey was performed on a total of 238 health students attending three universities in Chungcheong Province. An online survey was conducted on them using Naver Form from May 3 to 30, 2021. The questionnaire consisted of 14 questions about the class quality and type of non-face-to-face lectures such as preferred class content, learning environments, and interaction, 4 questions about perceived learning achievements, and 4 questions about class satisfaction with the students. Statistical analysis was performed using one-way ANOVA and Pearson correlation analysis.

Result: The survey results showed that satisfaction with non-face-to-face classes was 14.06 out of 25 . As for the scores for each sub-factor, the quality of class was in the order of learning environments (22.27 points), learning content (19.01 points), and interaction (10.33 points). Learning achievements were 28.27 points and learning sentiments were 16.59 points. As for the learning sentiments in a non-face-to-face class, 'Simple Class Materials' showed the highest score with 19.00 points, followed by 'Video Lectures Using PPT' with 17.18 points ( $\mathrm{p}=0.001$ ). In terms of learning achievements, 'Video Lecture Using PPT' was the highest with 29.32 points $(p=0.014)$. Lecture types showed little significant differences in the quality of class $(P>0.05)$. It was found that there was a significant positive correlation between class quality, learning achievements, and learning sentiments.

Conclusion: In the study, the class type with the highest satisfaction with the students was found to be an LMS (e-learning) recorded lecture, while the class type with the lowest satisfaction was a real-time video lecture in a non-face-to-face class for health students. Considering the findings showing that there is a positive correlation between the quality of non-face-to-face classes, learning achievements, and learning sentiments, it was suggested that non-face-to-face classes should reflect the class content as well as the curriculum and educational environments in order to improve students' satisfaction with the classes.
\end{abstract}

Keywords: COVID-19, Non-face-to-face classes, Class quality, Learning achievements, Learning sentiments, Class satisfaction

Copyright (C) 2021. Korean Academy of Preventive Dentistry. All rights reserved.

This is an Open Access article distributed under the terms of the Creative Commons Attribution Non-Commercial License (http://creativecommons.org/licenses/ by-nc/4.0) which permits unrestricted non-commercial use, distribution, and reproduction in any medium, provided the original work is properly cited. 